\title{
$\mathrm{MR}$ 유체와 압전스택을 이용한 능동 엔진마운트 시스템의 HILS 제어
}

\section{Control of Active Engine Mount System Featuring MR Fluid and Piezostack via HILS}

\author{
이 동 영*.최 승 복 \\ Dong-Young Lee and Seung-Bok Choi \\ (2009년 9월 21일 접수 ; 2009년 11월 24일 심사완료)
}

\begin{abstract}
Key Words : Engine(엔진), Hybrid Engine Mount(하이브리드 엔진마운트), MR Fluid(MR 유체), Piezostack Actuator(압전작동기), Sliding Mode Control(슬라이딩 모드 제어기), Hardware-in-the-loopsimulation(실시간 실물 모의실험)
\end{abstract}

\begin{abstract}
This paper presents vibration control performance of active engine mount system installed with the magneto-rheological(MR) mount and the piezostack mount. The performance is evaluated via hardware-in-the-loop-simulation(HILS) method. As a first step, six degrees-of freedom dynamic model of an in-line four-cylinder engine which has three point mounting system is derived by considering the dynamic behaviors of MR mount and piezostack mount. As a second step, sliding mode controller(SMC) is synthesized to actively control the imposed vibration. In order to demonstrate the effectiveness of the proposed active engine mount, vibration control performances are evaluated under various engine operating speeds(wide frequency range) using HILS method and presented in time and frequency domain.
\end{abstract}

\section{1. 서 론}

자동차 기술이 발달함에 따라 차량의 경량화, 엔 진의 고출력화 추세로 가고 있으며, 이에 따라 종전 보다 높은 소음과 진동 문제를 발생시키며, 이 소음 과 진동은 운전자의 승차감에 큰 영향을 미치게 한 다. 이러한 차량의 진동과 소음원 중의 하나는 엔진 구동계로 자동차 엔진에서 발생하는 가스폭발과 불 균형력은 차량의 소음과 진동의 큰 원인이 된다. 따 라서 엔진에서 발생하는 자동차의 소음과 진동문제 를 해결하기 위해 우수한 진동절연성능을 가진 엔 진마운트의 설계와 제어에 대한 연구와 개발이 활

† 교신저자; 정회원, 인하대학교 기계공학부

E-mail : seungbok@inha.ac.kr

Tel : (032)860-7319, Fax : (032)868-1716

* 인하대학교 기계공학과
발히 진행되고 있다 ${ }^{(1,2)}$.

최근에는 MR 유체(magneto-rheological fluid), ER 유체(electro-rheological fluid), 압전소재(piezoelectric material)등의 지능재료를 이용한 새로운 형태의 엔 진마운트에 대한 연구가 활발히 진행되고 있다. 특 히 MR 유체를 이용한 $\mathrm{MR}$ 마운트는 반능동형 엔 진마운트로 댐핑값을 조절 할 수 있어 효과적인 진 동절연이 가능하고 특히 저주파수 대역에서 뛰어난 진동절연. 성능을 보인다. 또한 압전소재를 이용한 압전스택 마운트는 능동형 엔진마운트로 시스템에 에너지를 공급 함으로서 효과적인 진동절연이 가능 하고 특히 높은 주파수 대역에서 효과적이다 ${ }^{(3 \sim 5)}$.

하지만 지금까지의 연구는 6-DOF 이상의 자유도 로 거동되는 실제 시스템을 1-DOF 시스템으로 가정 한 모델의 한계로 인해 실제시스템에서의 진동절연 성능을 평가하기가 어렵다. 따라서 보다 효과적인 진 
동과 소음의 절연을 위해서는 새로운 형태의 능동 엔진마운트 시스템의 모델링과 실험방법이 필요하다.

엔진마운트를 장착한 엔진마운트 시스템을 효과 적으로 개발하기 위해서는 실차실험을 통하여 분석 하는 것이 가장 바람직하나 이를 위해서는 실차시 험에 따른 시간적 비용적 문제가 발생하게 되어 비 효율적인 방법이 될 수도 있다. 이러한 문제를 해결 하고자 최근 활발히 사용되고 있는 방법으로는 실 시간 실물 모의실험(HILS : hardware-in-the-loopsimulation)이 있다. HILS방법은 개발초기단계부터 실제 시스템과 이론 모델을 결합하여 실시간 시뮬 레이션을 통하여 시스템의 성능을 평가하므로 이론 모델을 토대로 한 컴퓨터 시뮬레이션보다 실제 시 스템의 성능에 가깝게 성능평가를 할 수 있다 ${ }^{(6,7)}$.

이 연구에서는 엔진마운트 시스템의 효과적인 진 동절연을 위해 MR 마운트와 압전스택마운트를 고려 한 4실린더 4행정 가솔린 엔진마운트 시스템의 6자 유도 강체운동을 고려한 모델을 설정하였다. 롤마운 트로는 저주파수 대역에서 성능이 좋은 $\mathrm{MR}$ 엔진 마 운트를 적용하였고 RH(right-hand)마운트로는 고주파 수 대역에서 성능이 좋은 압전스택 마운트를 적용하 였다. 그리고 외란에 강건한 슬라이딩 모드 제어기를 설계 한 후 HILS 통해 제안 된 엔진마운트 시스템의 진동제어 성능을 시간영역과 주파수영역에서 평가하 였다.

\section{2. 엔진마운트 시스템의 모델링}

\section{1 전체 시스템의 모델링}

이 연구에서 제안된 $\mathrm{MR}$ 마운트와 압전스택마운트 를 적용한 엔진마운트 시스템은 Fig. 1과 같이 6자

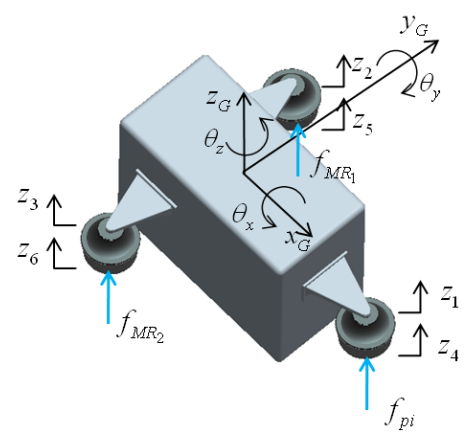

Fig. 1 Configuration of the engine mount system
유도의 강체운동을 하며 3점 지지 방식으로 엔진, $\mathrm{MR}$ 마운트 2개 $\left(f_{M R 1}, f_{M R 2}\right)$, 압전스택마운트 1개 $\left(f_{p i}\right)$ 로 구성되어 있고 가진원으로는 엔진에서 발생 되는 가진력이 작용된다고 모델링하였다. Fig. 1으로 부터 엔진마운트 시스템의 동적 지배방정식을 유도 하면 다음과 같이 나타낼 수 있다.

$$
m \ddot{x}_{G}+\left(c_{11}+c_{15}+c_{16}\right) \dot{x}_{G}+\left(k_{11}+k_{15}+k_{16}\right) x_{G}=F_{x}
$$

$$
m \ddot{y}_{G}+\left(c_{22}+c_{24}+c_{26}\right) \dot{y}_{G}+\left(k_{22}+k_{24}+k_{26}\right) y_{G}=F_{y}
$$

$$
\begin{gathered}
m \ddot{z}_{G}+\left(c_{33}+c_{34}+c_{35}\right) \dot{z}_{G}+\left(k_{33}+k_{34}+k_{35}\right) z_{G} \\
=F_{z}+f_{M R_{1}}+f_{M R_{2}}+f_{p i}
\end{gathered}
$$

$$
\begin{aligned}
& I_{x x} \ddot{\theta}_{x}+\left(c_{42}+c_{43}+c_{44}+c_{45}+c_{46}\right) \dot{\theta}_{x} \\
& +\left(k_{42}+k_{43}+k_{44}+k_{45}+k_{46}\right) \theta_{x}=T_{t}+b_{2} f_{M R_{1}}+b_{3} f_{M R_{2}}
\end{aligned}
$$

$$
\begin{aligned}
I_{y y} \ddot{\theta}_{y} & +\left(c_{51}+c_{53}+c_{54}+c_{55}+c_{56}\right) \dot{\theta}_{y} \\
& +\left(k_{51}+k_{53}+k_{54}+k_{55}+k_{56}\right) \theta_{y} \\
& =M_{y}-a_{2} f_{M R_{1}}-a_{3} f_{M R_{2}}-a_{1} f_{p i} \\
I_{z z} \ddot{\theta}_{z} & +\left(c_{61}+c_{62}+c_{64}+c_{65}+c_{66}\right) \dot{\theta}_{z} \\
& +\left(k_{61}+k_{62}+k_{64}+k_{65}+k_{66}\right) \theta_{z}=M_{z}
\end{aligned}
$$

여기서 $m$ 은 엔진의 질량이고 각각의 강성과 댐핑 은 다음과 같이 나타낼 수 있다.

$$
\begin{aligned}
& \mathrm{k}_{11}=\sum_{i=1}^{n} \mathrm{k}_{\mathrm{x}_{\mathrm{i}}}, \mathrm{k}_{15}=\sum_{i=1}^{n}\left(\mathrm{c}_{\mathrm{i}} \mathrm{k}_{\mathrm{x}_{\mathrm{i}}}\right), \mathrm{k}_{16}=\sum_{i=1}^{n}\left(-\mathrm{b}_{\mathrm{i}} \mathrm{k}_{\mathrm{x}_{\mathrm{i}}}\right) \\
& \mathrm{k}_{22}=\sum_{i=1}^{n} \mathrm{k}_{\mathrm{y}_{\mathrm{i}}}, \mathrm{k}_{24}=\sum_{i=1}^{n}\left(-\mathrm{c}_{\mathrm{i}} \mathrm{k}_{\mathrm{y}_{\mathrm{i}}}\right), \mathrm{k}_{26}=\sum_{i=1}^{n}\left(\mathrm{a}_{\mathrm{i}} \mathrm{k}_{\mathrm{y}_{\mathrm{i}}}\right) \\
& \mathrm{k}_{33}=\sum_{i=1}^{n} \mathrm{k}_{\mathrm{z}_{\mathrm{i}}}, \mathrm{k}_{34}=\sum_{i=1}^{n}\left(\mathrm{~b}_{\mathrm{i}} \mathrm{k}_{\mathrm{z}_{\mathrm{i}}}\right), \mathrm{k}_{35}=\sum_{i=1}^{n}\left(-\mathrm{a}_{\mathrm{i}} \mathrm{k}_{\mathrm{z}_{\mathrm{i}}}\right) \\
& \mathrm{k}_{44}=\sum_{i=1}^{n}\left(\mathrm{c}_{\mathrm{i}}{ }^{2} \mathrm{k}_{\mathrm{y}_{\mathrm{i}}}+\mathrm{b}_{\mathrm{i}}{ }^{2} \mathrm{k}_{\mathrm{z}_{\mathrm{i}}}\right), \mathrm{k}_{45}=\sum_{i=1}^{n}\left(-\mathrm{a}_{\mathrm{i}} \mathrm{b}_{\mathrm{i}} \mathrm{k}_{\mathrm{z}_{\mathrm{i}}}\right) \\
& \mathrm{k}_{55}=\sum_{i=1}^{n}\left(-\mathrm{a}_{\mathrm{i}} \mathrm{c}_{\mathrm{i}} \mathrm{k}_{\mathrm{y}_{\mathrm{i}}}\right) \\
& \left.\left.\mathrm{k}_{66}=\sum_{i=1}^{2} \mathrm{k}_{\mathrm{z}_{\mathrm{i}}}+\mathrm{c}_{\mathrm{i}}{ }^{2} \mathrm{k}_{\mathrm{x}_{\mathrm{i}}}\right), \mathrm{k}_{56} \mathrm{k}_{\mathrm{x}_{\mathrm{i}}}+\mathrm{a}_{\mathrm{i}}{ }^{2} \mathrm{k}_{\mathrm{y}_{\mathrm{i}}}\right)
\end{aligned}
$$




$$
\begin{aligned}
& \mathrm{c}_{11}=\sum_{i=1}^{n} \mathrm{c}_{\mathrm{x}_{\mathrm{i}}}, \mathrm{c}_{15}=\sum_{i=1}^{n}\left(\mathrm{c}_{\mathrm{i}} \mathrm{c}_{\mathrm{x}_{\mathrm{i}}}\right), \mathrm{c}_{16}=\sum_{i=1}^{n}\left(-\mathrm{b}_{\mathrm{i}} \mathrm{c}_{\mathrm{x}_{\mathrm{i}}}\right) \\
& \mathrm{c}_{22}=\sum_{i=1}^{n} \mathrm{c}_{\mathrm{y}_{\mathrm{i}}}, \mathrm{c}_{24}=\sum_{i=1}^{n}\left(-\mathrm{c}_{\mathrm{i}} \mathrm{c}_{\mathrm{y}_{\mathrm{i}}}\right), \mathrm{c}_{26}=\sum_{i=1}^{n}\left(\mathrm{a}_{\mathrm{i}} \mathrm{c}_{\mathrm{y}_{\mathrm{i}}}\right) \\
& \mathrm{c}_{33}=\sum_{i=1}^{n} \mathrm{c}_{\mathrm{z}_{\mathrm{i}}}, \mathrm{c}_{34}=\sum_{i=1}^{n}\left(\mathrm{~b}_{\mathrm{i}} \mathrm{c}_{\mathrm{z}_{\mathrm{i}}}\right), \mathrm{c}_{35}=\sum_{i=1}^{n}\left(-\mathrm{a}_{\mathrm{i}} \mathrm{c}_{\mathrm{z}_{\mathrm{i}}}\right) \\
& \mathrm{c}_{44}=\sum_{i=1}^{n}\left(\mathrm{c}_{\mathrm{i}}{ }^{2} \mathrm{c}_{\mathrm{y}_{\mathrm{i}}}+\mathrm{b}_{\mathrm{i}}{ }^{2} \mathrm{c}_{\mathrm{z}_{\mathrm{i}}}\right), \mathrm{c}_{45}=\sum_{i=1}^{n}\left(-\mathrm{a}_{\mathrm{i}} \mathrm{b}_{\mathrm{i}} \mathrm{c}_{\mathrm{z}_{\mathrm{i}}}\right) \\
& \mathrm{c}_{55}=\sum_{i=1}^{n}\left(\mathrm{a}_{\mathrm{i}} \mathrm{c}_{\mathrm{i}} \mathrm{c}_{\mathrm{y}_{\mathrm{i}}}\right) \\
& \left.\left.\mathrm{c}_{66}=\sum_{\mathrm{z}_{\mathrm{i}}}+\mathrm{c}_{\mathrm{i}}{ }^{2} \mathrm{c}_{\mathrm{x}_{\mathrm{i}}}\right), \mathrm{c}_{56}{ }^{2} \mathrm{c}_{\mathrm{i}} \mathrm{c}_{\mathrm{x}_{\mathrm{i}}}+\mathrm{a}_{\mathrm{i}}{ }^{2} \mathrm{c}_{\mathrm{y}_{\mathrm{i}}}\right)
\end{aligned}
$$

\section{2 엔진 가진력}

엔진 동력계의 가진력은 엔진의 피스톤과 커넥팅 로드의 왕복운동에 의한 상-하 방향의 관성력, 가 스폭발에 의한 토크, 피스톤 질량 관성에 의한 토 크, 커넥팅로드에 의한 수정관성 토크로 나뉜다 ${ }^{(8,9)}$.

4사이클 4기통 인라인 엔진에서 엔진이 운동 할 때 피스톤과 커넥팅로드의 왕복운동에 의한 상 하 방 향의 관성력 $F_{z}$ 는 다음과 같이 나타낼 수 있다.

$$
F_{Z}=\frac{4 m_{p} r^{2} \omega^{2}}{l} \cos 2 \omega t
$$

여기서 $m_{p}$ 는 왕복질량, $r$ 은 크랭크 반경, $\omega$ 는 크 랭크 축의 회전속도, $l$ 은 커넥팅로드의 길이이다.

롤방향으로 작용하는 토크 $T_{t}$ 는 가스폭발에 의한 토크 $T_{p}$, 피스톤 질량 관성에 의한 토크 $T_{m}$, 커넥 팅로드에 의한 수정관성 토크 $T_{c}$ 의 합이 되고 다음 과 같이 구할 수 있다.

$$
\begin{aligned}
& T_{p}=A_{p} P\left(r \sin \omega t+\frac{r^{2}}{2 l} \sin 2 \omega t\right) \\
& T_{m}=-2 m_{P} r^{2} \omega^{2} \sin 2 \omega t \\
& T_{c}=-2 \frac{r^{2}}{l^{2}} \omega^{2}\left(l_{p} l_{q} m_{c}-I_{c}\right) \sin 2 \omega t \\
& T_{t}=T_{p}+T_{m}+T_{c}
\end{aligned}
$$

$A_{p}$ 는 피스톤의 면적, $P$ 는 피스톤의 가스압력, $l_{p}$ 는 크랭크 핀과 커넥팅로드의 질량중심과의 거리, $l_{q}$ 는 피스톤 핀과 커넥팅로드의 질량중심과의 거리, $m_{c}$ 는 커넥팅로드의 질량, $I_{c}$ 는 커넥팅로드의 관성 모멘트이다. $F_{x}, F_{y}, M_{y}, M_{z}$ 의 힘은 크지 않아 시 스템에 크게 영향을 미치지 못하므로 0 이라고 가정 하였다.

\section{3. 마운트 모델링}

이 연구에서 제안한 $\mathrm{MR}$ 마운트와 압전스택마운 트를 Fig. 2과 Fig. 3에 나타내었다. MR 마운트는 고무요소, 원형디스크, 코일, 커버, 하우징 등으로 구성된다. 수직방형의 운동이 발생할 때 코일이 감 긴 디스크 주변으로 MR 유체가 유동하게 되고 이 때 코일에 전류를 부하시키면 자기장이 형성되어 유동저항을 발생시켜 댐핑력이 발생하게 된다. 이때 발생하는 댐핑력은 다음과 같이 나타낼 수 있다.

$$
\begin{aligned}
f_{M R} & =f_{f}+f_{s} \\
& =\left(\Delta P_{c}+\Delta P_{\eta}\right) A_{d}+\tau A_{c} \\
& =\left(\frac{2 d}{L} \tau_{y}+\frac{12 \eta h}{L^{3} b} A_{d}\left(\dot{z}_{2}-\dot{z}_{5}\right)\right) A_{d}+\tau A_{c} \\
& =\frac{2 d}{L} \alpha\left(\frac{N I}{L}\right)^{\beta} A_{d}+\frac{12 \eta h}{L^{3} b} A_{d}^{2}\left(\dot{z}_{2}-\dot{z}_{5}\right)+\tau A_{c}
\end{aligned}
$$

여기서 $f_{s}$ 는 전단모드에 의한 힘, $f_{f}$ 는 유동모드 에 의한 힘, $\tau$ 는 $\mathrm{MR}$ 유체의 전단응력을 나타내며, $A_{c}$ 는 접촉면적, $\eta$ 는 $\mathrm{MR}$ 유체의 기본점성 계수이 고, $\Delta P_{c}$ 는 $\mathrm{MR}$ 유체에 자기장이 가해질 때 전단항 복응력에 의해 발생하는 압력차이고, $\Delta P_{\eta}$ 는 자기장 이 가해지지 않을 때 $\mathrm{MR}$ 의 점성에 의한 압력차이 다. $A_{d}$ 는 상부 챔버의 등가 피스톤 단면적, $b$ 는 디 스크 중심에서 $\mathrm{MR}$ 유체가 흐르는 유동통로의 중간 까지의 거리이다.

다음으로 압전스택마운트는 고무요소, 관성질량, 압전스택, 커버, 하우징으로 구성되고 압전작동기에 전압이 가해지면 압전작동기가 관성질량을 진동시 켜 관성력이 발생하게 되고 다음과 같이 나타낼 수 있다.

$$
f_{p i}=-m_{1} \ddot{z}_{7}
$$




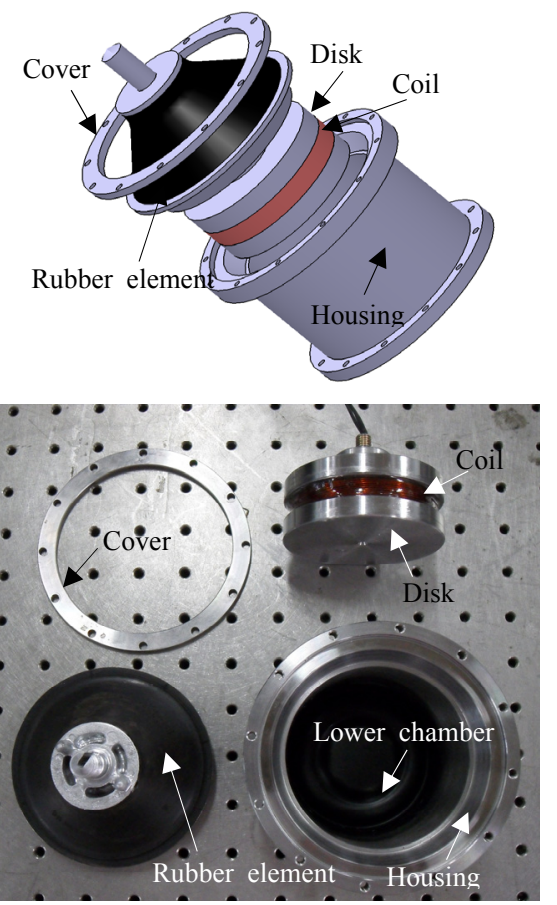

Fig. 2 Configuration of the MR engine mount
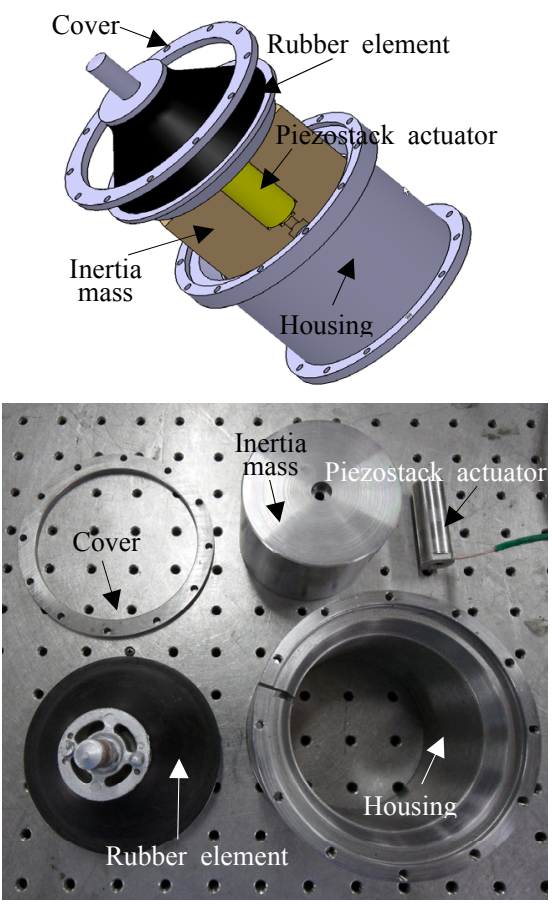

Fig. 3 Configuration of the piezostack engine mount

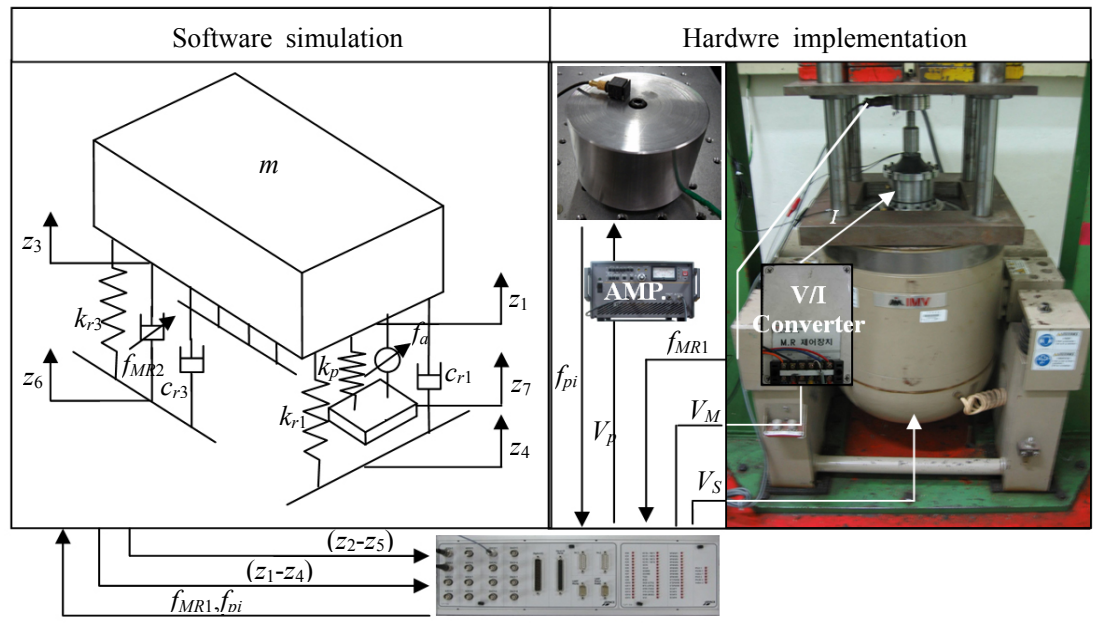

Fig. 4 HILS configuration of the engine mount system

Table 1 Specifications of each mount

\begin{tabular}{c|c}
\hline \hline Specification & Values \\
\hline MR mount stiffness & $132500 \mathrm{~N} / \mathrm{m}$ \\
\hline MR mount damping & $212 \mathrm{~N} \cdot \mathrm{s} / \mathrm{m}$ \\
\hline Piezo mount stiffness & $125250 \mathrm{~N} / \mathrm{m}$ \\
\hline Piezo mount damping & $167 \mathrm{~N} \cdot \mathrm{s} / \mathrm{m}$ \\
\hline Piezo mount inertia mass & $2 \mathrm{~kg}$ \\
\hline
\end{tabular}

여기서 $m_{1}$ 은 압전스택의 관성질이고 $z_{7}$ 은 압전스택 마운트 내부의 관성질량의 변위가 된다. 각각의 마 운트의 변수들은 Table 1에 나열하였다.

\section{4. 제어기 설계}

이 연구에서는 시스템의 고무요소의 비선형성, 압 
전작동기의 히스테리시스 등 시스템 불확실성과 파 라미터 변화, 외란에 대해 강건한 제어기를 설계하 기 위해 슬라이딩 모드 제어기를 설계하였다 ${ }^{(10)}$. 엔 진마운트 시스템의 운동방정식을 통해 제안된 모델 의 상태방정식은 다음과 같이 표현될 수 있다(11).

$$
\dot{x}=A x+B u_{c}+u_{e}
$$

엔진마운트 시스템에 들어가는 제어입력을 구하 기 위해 다음과 같이 슬라이딩 서피스를 설정한다.

$$
s=G x
$$

여기서, $G$ 는 슬라이딩 서피스의 기울기를 나타내는 벡터이며, 슬라이딩 모드가 존재하기 위해 다음의 조건을 만족해야 한다.

$$
\frac{1}{2} \frac{d}{d t} s^{2} \leq-\eta|s|, \quad(\eta \text { : strictly positive constant })
$$

따라서 슬라이딩 모드 제어기는 다음과 같이 설 계할 수 있다.

$$
\begin{gathered}
u_{c}=-(G B)^{-1}(G A x+k \cdot \operatorname{sgn}(s)),(k>0) \\
\operatorname{sgn}(s)= \begin{cases}-1, & s>0 \\
1, & s<0\end{cases}
\end{gathered}
$$

여기서, $k$ 는 불연속 게인을 나타내고, 식 (19)의 슬 라이딩 모드 제어기는 슬라이딩 모드 조건을 만족 한다. 그러나 이와 같은 불연속 제어기는 채터링을 발생 시키므로 정해진 경계조건 $\varepsilon$ 안에서 불연속 제 어기를 연속 제어기로 근사화하기 위해 부호함수를 다음과 같은 포화함수로 대체하면 다음과 같이 나 타낼 수 있다.

$$
\begin{gathered}
u=-(G B)^{-1}(G A x+k \cdot \operatorname{sat}(s)),(k>0) \\
\operatorname{sat}(s)=\left\{\begin{array}{cc}
s / \varepsilon, & |s| \leq \varepsilon \\
\operatorname{sgn}(s), & |s|>\varepsilon
\end{array}\right.
\end{gathered}
$$

이 연구에서 사용된 제어변수 값은 각각 $k=130$ $\varepsilon=0.05$ 이다.

\section{HILS 시스템의 구성 및 제어성능 고찰}

각각의 엔진마운트를 장착한 엔진마운트 시스템 의 HILS 시스템 구성도는 Fig. 4과 같이 나타낼 수 있다. 이 연구에서는 2 개의 MR 마운트와 1 개의 압 전스택마운트 중 2 번 마운트인 $\mathrm{MR}_{1}$ 마운트의 실제 뎀핑력을 측정하고 1 번 마운트인 압전스택마운트의 관성력을 측정하여 $\mathrm{HILS}$ 를 수행하였다. 시스템의 구성을 살펴보면 소프트웨어부에서 $\mathrm{MR}$ 마운트의 상대변위 $\left(z_{2}-z_{5}\right)$ 를 실시간으로 계산되어 하드웨 어부의 전자석 구동 가진기(IMV사, VS-2000-2)를 이용하여 장착된 $\mathrm{MR}$ 마운트에 동일한 변위가 발생 하도록 신호 $\left(V_{S}\right)$ 를 보낸다. 이 신호에 의해 MR 엔 진마운트는 상대변위를 발생시키고 동시에 이정보 를 토대로 계산 된 전압 $\left(V_{M}\right)$ 이 $\mathrm{V} / \mathrm{I}$ 컨버터를 통해 전류 $(I)$ 로 변화되어 $\mathrm{MR}$ 마운트에 공급된다. $\mathrm{MR}$ 마운트 내부의 코일에 공급된 전류는 $\mathrm{MR}$ 유체가 흐르는 유동통로에 자기장을 형성시켜 댐핑력을 발 생시킨다. 이때 발생된 댐핑력은 로드셸에서 측정되 어 소프트웨어부의 엔진마운트 시스템모델로 다시 입력된다. 이와 동시에 소프트웨어부에는 압전스택 마운트의 상대변위 $\left(z_{1}-z_{4}\right)$ 를 실시간으로 계산하고 이 정보를 토대로 하드웨어부의 압전스택에 전압 $\left(V_{p}\right)$ 을 공급한다. 이때 압전스택이 전압공급에 의해 작동되고 연결된 관성질량이 진동을 하게 된다. 가 속도센서를 통해 운동하는 관성질량의 가속도 값을 측정하고 이 값에 관성질량 값을 곱한 값인 관성력 값이 소프트웨어부의 엔진마운트 시스템 모델로 다 시 입력된다. 이렇게 입력된 정보들을 통해 소프트 웨어 부에서는 엔진마운트 시스템의 거동변화를 실 시간으로 계산한다.

$\mathrm{MR}$ 마운트와 압전스택마운트가 장착된 엔진마운 트 시스템의 진동제어성능을 고찰하기 위해 먼저 각각의 단품에 대한 평가를 먼저 하였다. Fig. 5, Fig. 6은 각각의 마운트의 주파수영역에서의 제어성 능을 나타낸다. 결과를 살펴보면 $\mathrm{MR}$ 마운트는 저 주파수 영역에서 압전스택마운트는 고주파수 영역 에서 좋은 성능을 나타내는 것을 확인 할 수 있다. Fig. 7에서 Fig. 9까지는 이 연구에서 제안한 슬라이 딩 모드 제어기를 사용한 엔진마운트 시스템에 대 한 HILS를 수행한 결과를 나타내었다. 제어력은 2 초 이후에 제어기를 통해 각각의 마운트로 부하되 었다. Fig. 7 에는 엔진의 공회전 $(750 \mathrm{rpm})$ 시의 엔진 의 무게중심점에서의 수직방향과 롤방향의 시간 


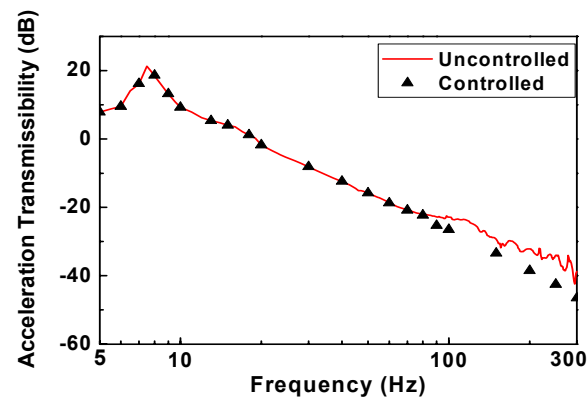

Fig. 5 Frequency response of the piezostack mount

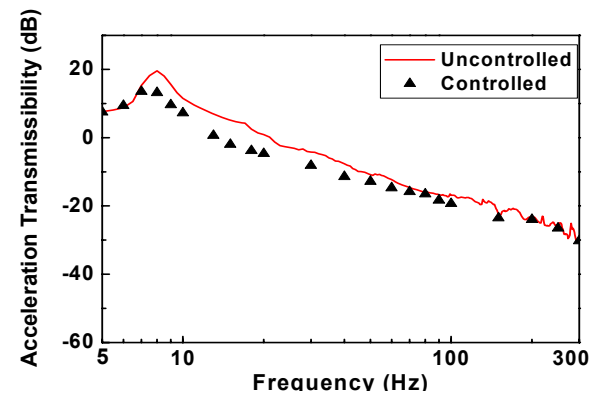

Fig. 6 Frequency response of the MR mount

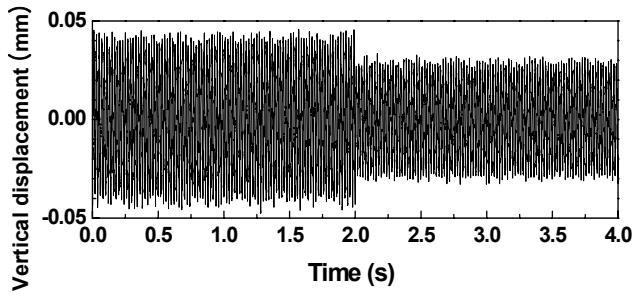

(a) Vertical displacement

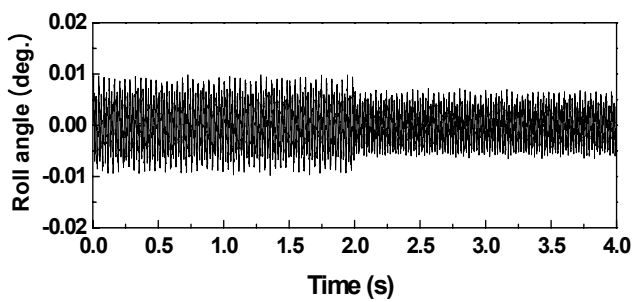

(b) Roll angle

Fig. 7 Vibration control response at $\mathrm{CG}(750 \mathrm{rpm})$

영역에서의 제어성능을 나타내었다. 결과를 보면 각 각 $17 \%, 48 \%$ 감소한 것을 확인 할 수 있다. Fig. 8 에는 $2000 \mathrm{rpm}$ 에서의 진동저감 성능을 나타내었고 고주파수 영역에서도 효과적인 절연이 가능함을 확 인 할 수 있다. Fig. 9에는 엔진의 무게중심점에서의

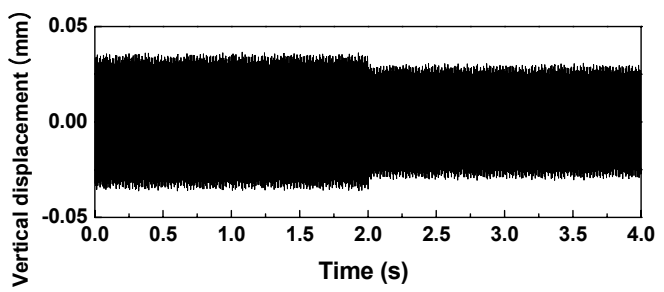

(a) Vertical displacement

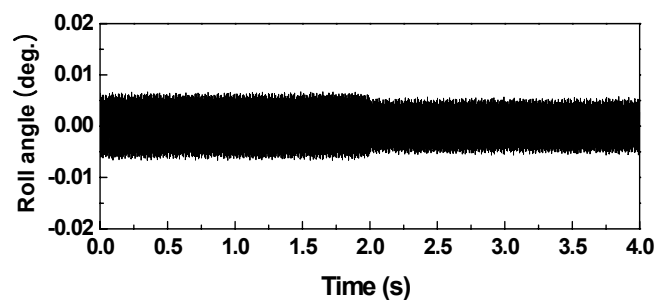

(b) Roll angle

Fig. 8 Vibration control response at $\mathrm{CG}(2000 \mathrm{rpm})$

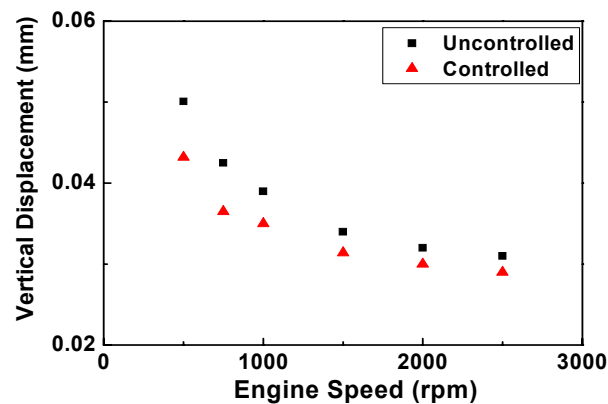

(a) Vertical displacement

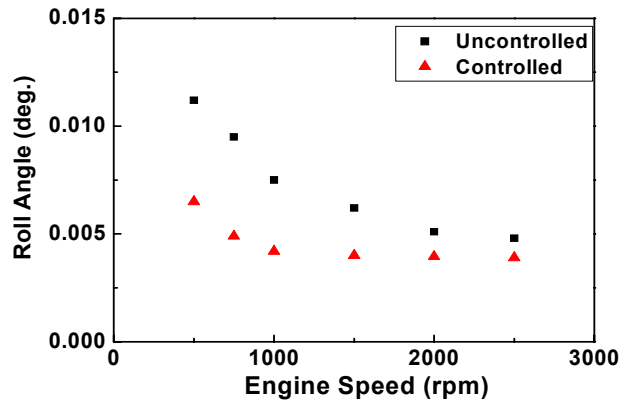

(b) Roll angle

Fig. 9 Frequency response at $\mathrm{CG}$

수직방향과 롤방향의 주파수영역에서의 제어성능을 나타내었다. 결과를 보면 전 주파수 영역에 걸쳐 롤 방향과 수직방향의 진동이 저감된 것을 확인 할 수 있다. 


\section{6. 결 론}

이 연구에서는 엔진의 진동을 감소시키기 위한 압전스택마운트와 MR 마운트로 구성된 새로운 형 태의 엔진마운트 시스템을 제안하고 실험을 통해 진동저감 성능을 평가하였다. 먼저, 엔진마운트 시 스템의 동적 모델을 해석 하였고 각각의 마운트를 모델링 하였다. 효과적인 진동제어를 위해 외란에 강건한 슬라이딩 모드 제어기를 설계 후 HILS 시 스템을 구축 한 뒤 실험을 수행하여 진동제어 성능 을 평가하였다. 다양한 주파수 범위에서 진동이 효 과적으로 줄어들었음을 확인 하였다.

\section{후 기}

이 연구는 지식경제부와 한국과학기술재단의 전 략기술인력양성사업으로 수행된 연구결과입니다.

\section{참 고 문 헌}

(1) Yu, Y., Naganathan, N. G., Dukkipati, R. V., 2001, "A Literature Review of Automotive Vehicle Engine Mounting Systens," Mechanism and Machine Theory, Vol. 36, pp. 123 142.

(2) Bernuchon, M., 1984, "A New Generation of Engine Mounts," SAE, 840259, pp. 230 236.

(3) Hong, S. R. and Choi, S. B., 2005, "Vibration Control of a Structural System Using Magnetorheological Fluid Mount," Journal of Intelligent Material System and Structures, Vol. 16, No. 11-12, pp. 931 936.

(4) Yook, J. Y., Choi, S. B., Sung, K. G. and Moon, S. J., 2007, "Design of Hybrid Mount Using
Rubber Element and Piezoelectric Actuator with Application to Vibration Control," Transactions of the Korean Society for Noise and Vibration Engineering, Vol. 17, No. 5, pp. 390 397.

(5) Jolly, M. R., Bender, J. W. and Carlson, J. D., 1998, "Properties and Applications of Commercial Magneto rheological Fluids," Proceedings of the SPIE's 5th Annual Symposiumon Smart Structuresand Materials, Vol. 3327, pp. 262 275.

(6) An, C. S., Choi, Y. T. and Choi, S. B., 1998, "Performance Evaluation of ER Suspension System via HILS," Transactions of the Korean Society of Mechanical Engineering, Vol. 22, No.11, pp. 2061 2071.

(7) Misselhorn, W. E., Theron, N. J. and Els, P. S., 2006, "Investigation of Hardware-in-loop for Use in Suspension development," Vehicle System Dynamics, Vol. 44, No. 1, pp. 65 81.

(8) Taylor, C. F., 1995, "The internal Combustion Engine in Theory and Practice," Vol. 2, Chp. 8, M.I.T. Press.

(9) Seki, Y. and Suzuki, T., 2001, "How to Predict Powertrain Vibration at the Engine Mounting Points under Running Conditions," SAE 2001-011592, pp. 1 5.

(10) Hui, S. and Zak, S. H., 1992, "Robust Control Synthesis for Uncertain/nonlinear Dynamical System," Automatica, Vol. 22, No. 2, pp. 289 298.

(11) Lee, D. Y., Sohn, J. W. and Choi, S. B., 2009, "A New Type of Active Engine Mount System Featuring MR Fluid and Piezostack," Transactions of the Korean Society for Noise and Vibration Engineering, Vol. 19, No. 6, pp. 583 590. 